\title{
Analysis of Contaminants in Vehicle Maintenance and Repair Enterprise
}

\author{
Jian Guo ${ }^{1, a}$, Chun-peng Wang ${ }^{2, b}$ \\ ${ }^{1}$ School of Mechanical Engineering, Binzhou Polytechnic, Binzhou 256603, China \\ ${ }^{2}$ School of Electrical Engineering, Binzhou Polytechnic, Binzhou 256603, China \\ a232463158@qq.com, bfuwa08@163.com
}

\begin{abstract}
The increase in vehicle ownership has led to an increase in the number of auto repair companies. However, people have neglected the pollution caused by auto repair companies during the maintenance process. This paper analyzes the $4 \mathrm{~S}$ shop and a class of maintenance companies and analyzes the company's maintenance process. The pollutants produced and the pollutants produced by them were subjected to predictive analysis, and the atmospheric pollutants were found to be spray paint exhaust gas, grinding dust and welding fumes and their corresponding values. The noise source intensity was 55-65 $\mathrm{dB}(\mathrm{A})$; This article can provide a reference for the environmental impact assessment of auto repair companies.
\end{abstract}

Keywords: Automobile, Contaminants, Spray paint, Noise.

\section{Introduction}

One type of auto repair business is mainly based on $4 \mathrm{~S}$ shops and some large-scale repair shops[1,2]. It is engaged in vehicle overhaul and assembly repairs, and may also be engaged in vehicle maintenance, minor repairs, and special repairs $[3,4]$.

One type of automotive repair service business, including engine repair, body correction, oil supply system maintenance and oil replacement, electrical system maintenance, tire dynamic balance and repair, four-wheel alignment testing and adjustment, air conditioning maintenance, sheet metal, touch up paint, etc[5-8]. Oil, waste water, hazardous waste, exhaust gas and other pollutants will be generated. See Fig 1 Detailed process flow and the resulting pollutants in the Garage and Fig 2 Technological process and the resulting pollutants of sheet metal painting process.

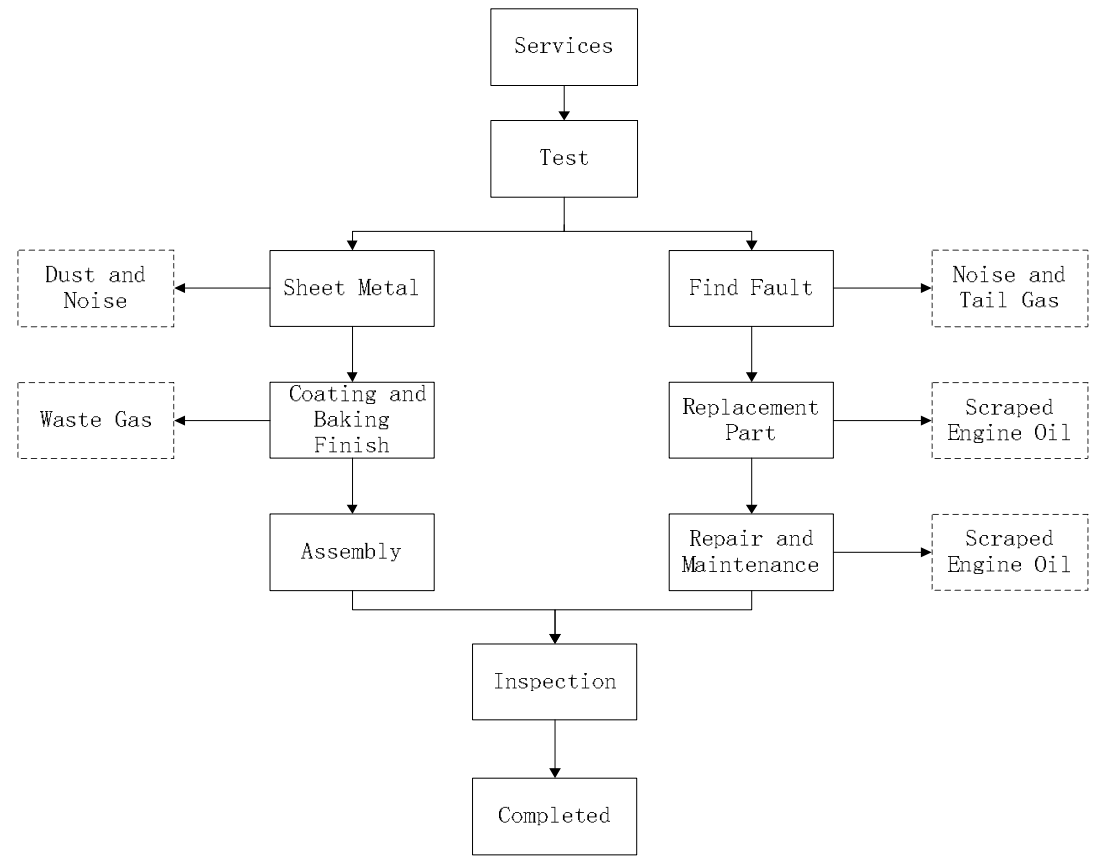

Fig 1 Process flow and resulting pollutants in the garage 


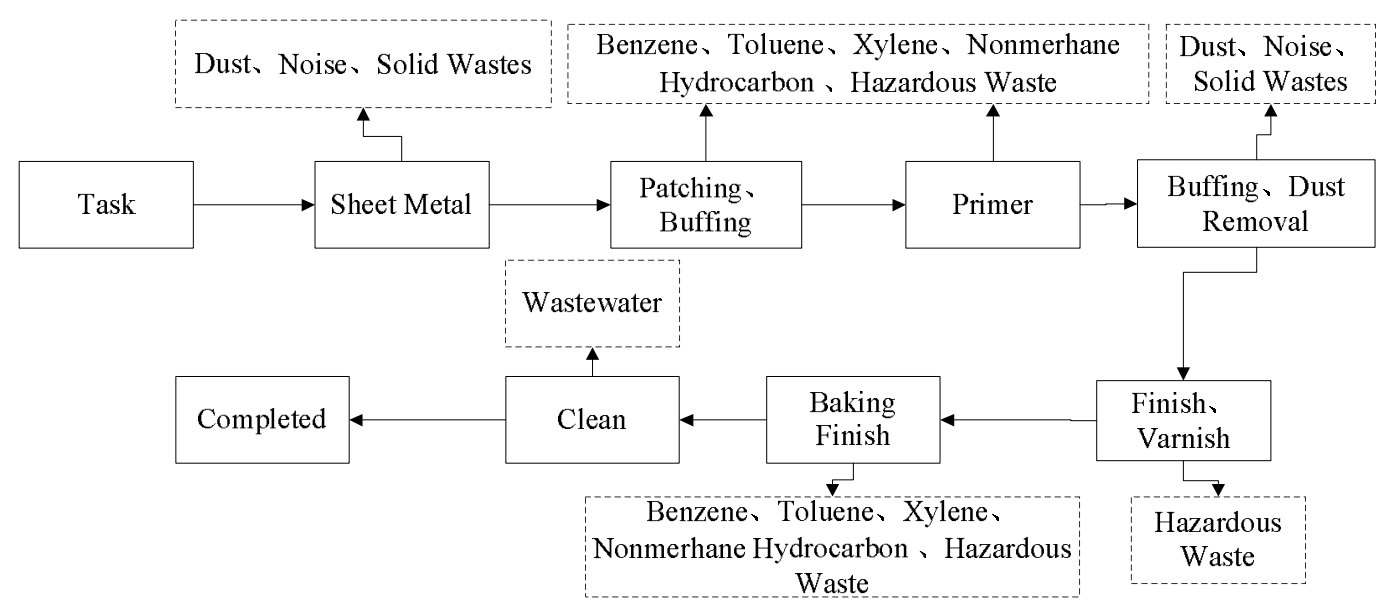

Fig 2 Technological process and resulting pollutants of sheet metal painting process

One of them sprays the vehicle, the sheet metal process and the putty, and then uses the grinding equipment to manually polish it, then uses the special paint to make up the sand, and then after grinding, it enters the spray paint booth to spray the primer, and then plays the tracheotomy gray and spray paint $[9,10]$.

\section{Process analysis of pollutants generated}

Waste water mainly includes cleaning sites, car wash water and domestic sewage. The maintenance workshop clean effluent contains certain suspended solids, organic matter, petroleum, etc. The domestic sewage is used for hand washing and toilet flushing. The main pollution factors for sewage are $\mathrm{COD}_{\mathrm{cr}} \mathrm{BOD}_{5} \mathrm{SS}$, ammonia nitrogen and petroleum.

The source of atmospheric pollution is the exhaust gas generated by spray booths and the dust generated by maintenance workshops, welding fumes, and other pollutants.

Paints used in paint houses include primers, paints and varnishes. Primers and color paints are water-based paints, and varnish is a volatile paint. The main components of water-based paint are resin and water, and there are a small amount of etchers, alcohols and stones, and do not contain organic solvents such as benzene and toluene.

About $60 \%$ of the solid content is attached to the paint surface during the painting process, and the remaining $40 \%$ of the solid content is transformed into paint mist. The national regulations stipulate that the low volatile organic content paint such as water-based paint accounts for not less than $80 \%$ of the total paint usage.

After repairing the vehicle's putty, the repair workshop grinds it with a dry grinding device to generate dust containing exhaust gas in the surrounding area. The dust particle diameter is $5-10 \mu \mathrm{m}$, and the exhaust gas volume is smaller by about the volumes of $100 \mathrm{~m}^{3}$. However, its high concentration, concentration of about $500 \mathrm{mg} / \mathrm{m}^{3}-700 \mathrm{mg} / \mathrm{m}^{3}$, the body can be breathed into the respiratory hazard.

In the welding process, the $\mathrm{CO}_{2}$ protection welding machine will generate welding fumes. After the welding fumes are diluted in the workshop air, the concentration of welding fumes in the maintenance workshop air is low.

The noise mainly comes from spray booth exhaust fans, machine repair equipment, air compressor equipment operation noise, sheet metal operations and so on. The noise source intensity of the paint exhaust fan is about $77 \mathrm{~dB}(\mathrm{~A})$, the noise source strength of the machine repair equipment is about $75 \sim 80 \mathrm{~dB}(\mathrm{~A})$, and the noise source strength of the air compressor is about $80 \mathrm{~dB}(\mathrm{~A})$. The noise is mostly sudden transient noise, and the source intensity is about $85 \sim 95 \mathrm{~dB}(\mathrm{~A})$.

Solid waste is mainly domestic waste, general industrial solid waste, and hazardous waste. The general industrial solid waste generated during the vehicle maintenance process includes used tires, waste packaging materials, and other scrap components. The hazardous wastes are mainly waste mineral oils (gasoline, diesel oil, engine oil, lubricating oil, cotton cloth contaminated with oil, etc.), 
paints, dye wastes (waste paint, waste thinners, waste paint slag, filter cotton after use in spraying booths, etc.) Activated carbon, etc.), waste organic solvents (waste organic solvents generated during the cleaning of parts, waste cleaning agents, waste antifreeze used for vehicle maintenance and replacement, etc.), and other wastes (waste paint buckets, paint cans, waste oil barrels, etc. Electronic components, circuit boards, etc.) Waste lead-acid batteries (storage batteries).

\section{Forecast analysis}

Most auto repair companies and auto 4S shops are located in urban suburbs, far away from residential areas. This paper implements Surface Water Environmental Quality Standard GB3838-2002 for surface water environmental quality standards.IVWater quality standards, environmental air quality implementation of the "Ambient Air Quality Standards" (GB3095-2012) in the secondary standards, the implementation of the "acoustic environment quality standards" (GB3096-2008) in the category 2 area standards, the resulting danger The wastes were implemented in 11 automobile 4S shops under the "Control Standards for Storage Pollution of Hazardous Wastes" (GB18597-2001), and 9 auto repair companies were surveyed and forecasting. The major pollutants produced by averaging them and their predicted discharge status are shown in the Table 1.

Table 1 The main pollutants emissions and predicted

\begin{tabular}{|c|c|c|c|c|}
\hline Types of & Emission source & $\begin{array}{l}\text { Contaminant } \\
\text { name }\end{array}$ & $\begin{array}{l}\text { Concentration } \\
\text { and production }\end{array}$ & $\begin{array}{c}\text { Emission } \\
\text { concentration } \\
\text { and emissions }\end{array}$ \\
\hline \multirow{4}{*}{$\begin{array}{l}\text { atmospheric } \\
\text { pollutant }\end{array}$} & \multirow[b]{2}{*}{ Spray paint room } & Benzene series & $\begin{array}{c}6.46 \mathrm{mg} / \mathrm{m}^{3} \\
(0.15505 \mathrm{t} / \mathrm{a})\end{array}$ & $\begin{array}{l}0.646 \mathrm{mg} / \mathrm{m}^{3} \\
(0.0155 \mathrm{t} / \mathrm{a})\end{array}$ \\
\hline & & $\begin{array}{c}\text { Non-methane } \\
\text { total } \\
\text { hydrocarbons }\end{array}$ & $\begin{array}{l}23.29 \mathrm{mg} / \mathrm{m}^{3} \\
(0.55895 \mathrm{t} / \mathrm{a})\end{array}$ & $\begin{array}{l}2.329 \mathrm{mg} / \mathrm{m}^{3} \\
(0.0559 \mathrm{t} / \mathrm{a})\end{array}$ \\
\hline & \multirow[b]{2}{*}{ Repair shop } & Grinding dust & $\begin{array}{c}600 \mathrm{mg} / \mathrm{m}^{3} \\
102 \mathrm{~kg} / \mathrm{a}\end{array}$ & $\begin{array}{c}0.001 \mathrm{mg} / \mathrm{m}^{3} \\
1.02 \mathrm{~kg} / \mathrm{a}\end{array}$ \\
\hline & & Welding fumes & $\begin{array}{c}0.013 \mathrm{mg} / \mathrm{m}^{3} \\
(0.48 \mathrm{~kg} / \mathrm{a})\end{array}$ & $\begin{array}{c}0.013 \mathrm{mg} / \mathrm{m}^{3} \\
(0.48 \mathrm{~kg} / \mathrm{a})\end{array}$ \\
\hline \multirow{5}{*}{ Water pollutants } & \multirow{5}{*}{$\begin{array}{c}\text { Domestic } \\
\text { sewage, } \\
\text { maintenance } \\
\text { workshop clean } \\
\text { water }\end{array}$} & $\mathrm{COD}_{\mathrm{cr}}$ & $\begin{array}{c}290 \mathrm{mg} / \mathrm{L} \\
(0.0237 \mathrm{t} / \mathrm{a}) \\
\end{array}$ & $\begin{array}{c}29 \mathrm{mg} / \mathrm{L} \\
(0.0024 \mathrm{t} / \mathrm{a})\end{array}$ \\
\hline & & $\mathrm{BOD}_{5}$ & $\begin{array}{c}260 \mathrm{mg} / \mathrm{L} \\
(0.0212 \mathrm{t} / \mathrm{a})\end{array}$ & $\begin{array}{c}18 \mathrm{mg} / \mathrm{L} \\
(0.0015 \mathrm{t} / \mathrm{a})\end{array}$ \\
\hline & & SS & $\begin{array}{c}140 \mathrm{mg} / \mathrm{L} \\
(0.0114 \mathrm{t} / \mathrm{a})\end{array}$ & $\begin{array}{c}21 \mathrm{mg} / \mathrm{L} \\
(0.0017 \mathrm{t} / \mathrm{a})\end{array}$ \\
\hline & & $\begin{array}{l}\text { Ammonia } \\
\text { nitrogen }\end{array}$ & $\begin{array}{c}29 \mathrm{mg}(0.0024 \mathrm{t} / \mathrm{a}) \\
(0.0024 \mathrm{t} / \mathrm{a})\end{array}$ & $\begin{array}{c}12 \mathrm{mg} / \mathrm{L} \\
(0.001 \mathrm{t} / \mathrm{a})\end{array}$ \\
\hline & & oil & $\begin{array}{c}7 \mathrm{mg} / \mathrm{L} \\
(0.0006 \mathrm{t} / \mathrm{a})\end{array}$ & $\begin{array}{c}1 \mathrm{mg} / \mathrm{L} \\
(0.0001 \mathrm{t} / \mathrm{a})\end{array}$ \\
\hline \multirow{3}{*}{ Solid Waste } & Everyday life & Living garbage & $2.14 \mathrm{t} / \mathrm{a}$ & $2.14 \mathrm{t} / \mathrm{a}$ \\
\hline & \multirow[t]{2}{*}{ Repair shop } & $\begin{array}{l}\text { General solid } \\
\text { waste }\end{array}$ & $20 \mathrm{t} / \mathrm{a}$ & $20 t / a$ \\
\hline & & Hazardous Waste & $15.53 \mathrm{t} / \mathrm{a}$ & $15.53 \mathrm{t} / \mathrm{a}$ \\
\hline Noise & Repair shop & $60-95 \mathrm{~dB}(\mathrm{~A})$ & & \\
\hline
\end{tabular}

In order to prevent the excessive discharge of water pollutants, a type of auto repair enterprise has considered the problem of sewage discharge in the initial stage of construction. According to the "unit discharge standard for water pollutants in the automobile maintenance industry" (GB26877-2011), It is a small vehicle of $0.014 \mathrm{~m}^{3}$, the type of maintenance companies surveyed exceed this limit and have a low impact on the surrounding water environment.

According to investigations, when spray painting and paint mixing operations are performed on spray paint booths, unless exhaust gas treatment measures are taken, the exhaust gas emissions 
exceed the allowable emission standards. Therefore, if no measures are taken, spray paint booths will be detrimental to the local atmospheric environment. The impact, especially for direct operators, requires the use of appropriate purifying measures for the benzene series emitted from spray paint and paint conditioning operations.

The exhaust gas generated during the operation period of spray paint booths is subjected to adsorption treatment with supporting filter materials and is discharged from the exhaust pipe with a height greater than $15 \mathrm{~m}$ through a mechanical exhaust device. The concentration of each pollutant emitted from the exhaust gas during the operation period of the spray booth is Conforms to the "Emission Standard for Air Pollutants in the Automobile Maintenance Industry" (DB11/1228-2015).

The grinding process should be carried out in a relatively closed workshop. The dust produced is controlled by a mobile dust collector that is equipped with a dry mill. The dust removal efficiency is $99 \%$, and the concentration of grinding dust is averaged $600 \mathrm{mg} / \mathrm{m}^{3}$, after the purification of dust concentration $6 \mathrm{mg} / \mathrm{m}^{3}$, maintenance workshop area of $1000 \mathrm{~m}^{2}$, about $7 \mathrm{~m}$ floor height, after dilution in the maintenance shop air, grinding dust concentration of $0.001 \mathrm{mg} / \mathrm{m}^{3}$. The amount of grinding dust produced by the maintenance workshop of the project is approximately $102 \mathrm{~kg} / \mathrm{a}$. After the collection and purification treatment by the mobile dust collector, the dust emission of the grinding dust is $1.02 \mathrm{~kg} / \mathrm{a}$.

After the vehicle has been putty and polish with a dry grinding device, It will generate grinding dust in the surrounding area. After being cleaned by the mobile dust collector and diluted in the workshop air, It will be discharged in an unorganized manner in the maintenance workshop. It is estimated that there will be no organization monitoring. The concentration was $0.001 \mathrm{mg} / \mathrm{m}^{3}$.

After a small amount of welding fumes generated during the welding process was diluted in the air of the repair shop, the welding fumes were discharged unorganized with a concentration of $0.013 \mathrm{mg} / \mathrm{m}^{3}$ and met the "Integrated Emission Standard for Air Pollutants" (DB11/501-2007).

The attenuation formula caused by the increase of noise with distance:

$$
\Delta L=L_{1}-L_{0}=20 \lg \left(\frac{r_{1}}{r_{0}}\right)
$$

In the formula, $L_{1} 、 L_{0}$ Point-to-point sound source $r_{1} 、 r_{0}$ Noise value, $\mathrm{dB}(\mathrm{A}) ; r_{1} 、 r_{0}$ Is the distance (meters) from the noise source, $r_{0}$ Generally pointing away from the sound source 1 meter.

The superposition formula of $\mathrm{N}$ noise sources:

$$
L=10 \lg \left(10^{\frac{\mathrm{L}_{1}}{10}}+10^{\frac{\mathrm{L}_{2}}{10}}+\Lambda+10^{\frac{\mathrm{L}_{\mathrm{n}}}{10}}\right)
$$

In the formula, $L$ Total equivalent sound level, $\mathrm{dB}(\mathrm{A}) ; L_{0} 、 L_{1} 、 L_{n}$, They are the equivalent sound levels of $\mathrm{N}$ noise sources, $\mathrm{dB}(\mathrm{A})$.

According to the monitoring of $4 \mathrm{~S}$ shops and a class of auto repair companies, the prediction of the surrounding ambient noise is obtained by combining the equations above.

Table 2 The surrounding ambient noise predictive value

\begin{tabular}{|c|c|c|c|c|}
\hline Predicted location & East & South & West & North \\
\hline Monitoring background value & 62.2 & 53.1 & 52.6 & 52.9 \\
\hline Contribution & 14.4 & 30 & 30 & 50 \\
\hline Predictive value & 62.2 & 53.1 & 52.6 & 54.7 \\
\hline
\end{tabular}

After the noise is attenuated by the sound insulation and distance of the wall, the noise at the plant boundary complies with the "Emission Standard for Environmental Noise at the Boundary of Industrial Enterprises" (GB12348-2008).

Solid waste is recycled by a specialized material recovery unit. Domestic garbage is removed by the municipal sanitation department. It is cleared daily and no secondary pollution occurs. 


\section{Conclusion}

The main atmospheric pollutants of a type of maintenance enterprise are spray paint exhaust gas, grinding dust and welding fume, spray paint exhaust gases such as toluene, xylene and non-methane total hydrocarbon produced during the spray paint process. After filtration and adsorption treatment of the filter material supporting the spray paint room, it is discharged through the exhaust pipe with a height of $15 \mathrm{~m}$ or more. At the same time, the operator needs to do a good job of protection.

The intensity of the noise generated during the maintenance process is about $60-80 \mathrm{~dB}(\mathrm{~A})$, and the short-term noise source intensity generated by the sheet metal process is about $70-90 \mathrm{~dB}(\mathrm{~A})$. After the sound insulation of the building and the distance attenuation, the noise source Strong can be reduced to $55-65 \mathrm{~dB}(\mathrm{~A})$. It is recommended that $4 \mathrm{~S}$ stores and one type of maintenance enterprise should be located away from residential areas and college hospitals.

\section{References}

[1] Ground-level ozone in the Pearl River Delta and the roles of VOC and NOx in its production[J] . Min Shao,Yuanhang Zhang,Limin Zeng,Xiaoyan Tang,Jing Zhang,Liuju Zhong,Boguang Wang.Journal of Environmental Management . 2007 (1) 512-518.

[2] TVOC and Health in Non-industrial Indoor Environments[J] . Indoor Air . 2004 (2) 78-91.

[3] The characteristics and origins of carbonaceous aerosol at a rural site of PRD in summer of 2006[J] . Hu W. W.,Hu M.,Deng Z. Q.,Xiao R.,Kondo Y.,Takegawa N.,Zhao Y. J.,Guo S.,Zhang Y. H..Atmospheric Chemistry and Physics . 2012 (261) 1811-1822.

[4] Secondary organic aerosol formation from $\mathrm{m}$-xylene, toluene, and benzene[J] . Ng N. L.,Kroll J. H,Chan A. W. H.,Chhabra P. S.,Flagan R. C.,Seinfeld J. H.Atmospheric Chemistry and Physics . 2007 (98) 3909-3922.

[5] Advances in the science and technology of paints, inks and related coatings[J] . I Holme.Surface Coatings International Part B: Coatings Transactions . 2004 (4) 441-454.

[6] Study on emission characteristics of volatile organic compounds in the exhaust of different types of vehicles. LIANG Bao-sheng,et al (College of Environmental Sciences,Peking University,Beijing 100871,China). Environmental Monitoring In China . 2005 211-222.

[7] Hydrocarbon Source Apportionment for the 1996 Paso del Norte Ozone study. Fujita E M. Science of the Total Environment . 2001 171-184.

[8] Study on benzene,toluene,xylenepollution resulted fromvehicle emission. Xu D Q,Liu C M,Li Z. Journal of Environmentand Health . 2004 516-524.

[9] Volatile hydrocarbon emissions from vehicles and vertical ventilations in the Hsuehshan traffic tunnel, Taiwan[J] . Chia-Hsiang Lai,Yen-Ping Peng. Environmental Monitoring and Assessment . 2012 (7) 102-109.

[10]Emission characteristics of nonmethane hydrocarbons from private cars and taxis at different driving speeds in Hong Kong[J] . H. Guo,S.C. Zou,W.Y. Tsai,L.Y. Chan,D.R. Blake.Atmospheric Environment . 2011 (16) 2711-2721. 